\title{
The Effect of Curing Temperature on the Properties of Cement Pastes Modified with $\mathrm{TiO}_{2}$ Nanoparticles
}

\author{
Karine Pimenta Teixeira ${ }^{1}$, Isadora Perdigão Rocha ${ }^{1}$, Leticia De Sá Carneiro ${ }^{1}$, Jessica Flores ${ }^{1}$, \\ Edward A. Dauer ${ }^{2}$ and Ali Ghahremaninezhad ${ }^{1, *}$ \\ 1 Department of Civil, Architectural and Environmental Engineering, University of Miami, Coral Gables, \\ FL 33146, USA; karine.pimentateixeira@gmail.com (K.P.T.); isadora.perdigao@hotmail.com (I.P.R.); \\ leticia.carneiro@ufv.br (L.D.S.C.); j.flores7@umiami.edu (J.F.) \\ 2 Department of Biomedical Engineering, University of Miami, Coral Gables, FL 33146, USA; \\ edauer@miami.edu \\ * Correspondence: a.ghahremani@miami.edu; Tel.: +1-305-284-3465
}

Academic Editor: Silvia Gross

Received: 19 September 2016; Accepted: 15 November 2016; Published: 23 November 2016

\begin{abstract}
This paper investigates the effect of curing temperature on the hydration, microstructure, compressive strength, and transport of cement pastes modified with $\mathrm{TiO}_{2}$ nanoparticles. These characteristics of cement pastes were studied using non-evaporable water content measurement, X-ray diffraction (XRD), compressive strength test, electrical resistivity and porosity measurements, and scanning electron microscopy (SEM). It was shown that temperature enhanced the early hydration. The cement pastes cured at elevated temperatures generally showed an increase in compressive strength at an early age compared to the cement paste cured at room temperature, but the strength gain decreased at later ages. The electrical resistivity of the cement pastes cured at elevated temperatures was found to decrease more noticeably at late ages compared to that of the room temperature cured cement paste. SEM examination indicated that hydration product was more uniformly distributed in the microstructure of the cement paste cured at room temperature compared to the cement pastes cured at elevated temperatures. It was observed that high temperature curing decreased the compressive strength and electrical resistivity of the cement pastes at late ages in a more pronounced manner when higher levels of $\mathrm{TiO}_{2}$ nanoparticles were added.
\end{abstract}

Keywords: hydration; cement paste; elevated temperature; $\mathrm{TiO}_{2}$ nanoparticles

\section{Introduction}

Nanomaterials have the potential to revolutionize the construction industry by improving the performance and durability of construction materials, as well as imparting new functionalities to these materials [1-4]. Nanomaterials such as silica nanoparticles [5-10], carbon nanotubes [11-13], $\mathrm{TiO}_{2}$ nanoparticles [14-25], and clay nanoparticles [26-29] have been studied to investigate their effect on cementitious materials. The use of $\mathrm{TiO}_{2}$ nanoparticles in construction materials has been the focus of intense research in the recent years, primarily due to its self-cleaning and air-cleaning properties, arising from their photocatalytic characteristics [30,31]. Lackhoff et al. [14] showed an increase in the compressive strength of mortars containing $\mathrm{TiO}_{2}$ nanoparticles. The influence of $\mathrm{TiO}_{2}$ nanoparticles on the hydration of cementitious materials was examined by researchers [15-17] and shown to enhance hydration due to the high surface area of these nanoparticles, increasing the nucleation sites for the hydration reaction. Lee et al. [18] reported that compressive strength increased by up to $10 \% \mathrm{TiO}_{2}$ nanoparticle replacement at a low water-to-cement ratio (0.4) and did not show degradation at high water-to-cement ratios (0.6). Zhang et al. [19] demonstrated that $\mathrm{TiO}_{2}$ nanoparticles improved the compressive strength and mitigated the drying shrinkage of cementitious materials. In addition, the 
addition of $\mathrm{TiO}_{2}$ nanoparticles has been shown to improve the densification of the microstructure, thereby enhancing the durability of the cementitious materials $[20,23,25,32,33]$.

Due to variability in the environmental temperature during mixing and curing of cementitious materials in practice, it is important to understand how curing temperature influences the behavior of cementitious materials. In addition, high temperature curing is relevant in applications such as oil well cement and precast industry. Prior studies indicated an increase in the early age strength due to enhanced hydration in cementitious materials cured at elevated temperatures, compared to curing at room temperature [34-38]. However, a reduction in the compressive strength of cementitious materials, after the initial enhancement, was observed as a result of curing at elevated temperatures compared to the room temperature curing [34-37,39]. The effect of curing at high temperatures on the microstructure of cementitious materials was investigated and shown to promote increased porosity and induce heterogeneous distribution of hydration product in the microstructure of the materials [34,36,37,40-42]. Although the effects of $\mathrm{TiO}_{2}$ nanoparticles and curing temperature have been individually studied in the past, the effect of curing temperature on the behavior of cement paste modified with $\mathrm{TiO}_{2}$ nanoparticles has not received attention. In one particular recent study, Jayapalan et al. [43] indicated an increase in the temperature sensitivity of early age hydration of cementitious materials as a result of modification with $\mathrm{TiO}_{2}$ nanoparticles. However, the influence of curing temperature on the microstructure and properties of cementitious materials modified with $\mathrm{TiO}_{2}$ nanoparticles has not been examined in the past. Knowledge of this influence is important in the engineering of cementitious materials modified with nanoparticles in applications such as oil well cement and precast industry.

Therefore, this paper aims to address this knowledge gap by investigating the hydration, compressive strength, and transport behavior of cement paste modified with $\mathrm{TiO}_{2}$ nanoparticles, cured at varied temperatures. The hydration of cement pastes was evaluated using non-evaporable water content measurement. The compressive strength test was performed to investigate compressive strength. Electrochemical impedance spectroscopy (EIS) was utilized to determine the electrical resistivity of the cement pastes and used to infer their transport behavior. Porosity measurement was carried out using the methanol exchange method. Scanning electron microscopy (SEM) and X-ray diffraction (XRD) were conducted to gain insight into the microstructural characteristics of the cement pastes with $\mathrm{TiO}_{2}$ nanoparticles cured at elevated temperatures.

\section{Experiments}

\subsection{Materials and Specimen Preparation}

In this study, specimens were prepared using Type I Portland cement with the addition of $0.8 \%$, $2.5 \%$, and $5 \%$, per cement mass, $\mathrm{TiO}_{2}$ nanoparticles. The chemical composition of the cement is presented in Table 1. The $\mathrm{TiO}_{2}$ nanoparticles (PC105 from CRISTAL ACTIVTM, Hunt Valley, MD, USA) used in this study were the ultrafine and high purity anatase crystal phase with a surface area of about $90 \mathrm{~m}^{2} / \mathrm{g}$. The particle size analysis was performed on $0.5 \%$ by mass suspension $\mathrm{TiO}_{2}$ nanoparticles in distilled water using dynamic light scattering with Zetasizer Nano ZS (Malvern Instruments, Malvern, UK). The particle size distribution of $\mathrm{TiO}_{2}$ nanoparticles is shown in Figure 1a. It is seen that the particles are in the range of $1 \mu \mathrm{m}$. This size is similar to those reported in the previous studies on cement paste with $\mathrm{TiO}_{2}$ nanoparticles [18,43]. This is due to agglomeration occurring between $\mathrm{TiO}_{2}$ nanoparticles. An SEM image of $\mathrm{TiO}_{2}$ nanoparticles is presented in Figure 1b. It should be noted that the chemical characteristics, including $\mathrm{pH}$ and ionic strength, of cementitious mixtures have a profound effect on the dispersion of nanoparticles and, therefore, the particle size distribution in cementitious mixtures could differ from that shown in Figure 1a. It should be emphasized that there is variation in $\mathrm{TiO}_{2}$ nanoparticles depending on the manufacturing processes; the $\mathrm{TiO}_{2}$ nanoparticles were chosen for this study on the basis of their wide use in cement-based materials, their uniform size distribution and their applications as photocatalytic material. 
Table 1. Chemical composition of the cement.

\begin{tabular}{cc}
\hline \multicolumn{2}{c}{ Composition (\% by Mass) } \\
\hline Silica & 20.82 \\
Alumina & 4.98 \\
Iron oxide & 3.68 \\
Calcium oxide & 64.34 \\
Magnesium oxide & 0.91 \\
Sodium oxide & 0.19 \\
Potassium oxide & 0.41 \\
Sulfur trioxide & 2.79 \\
Titanium dioxide & 0.24 \\
Loss on ignition (LOI) & 2.03 \\
\hline
\end{tabular}

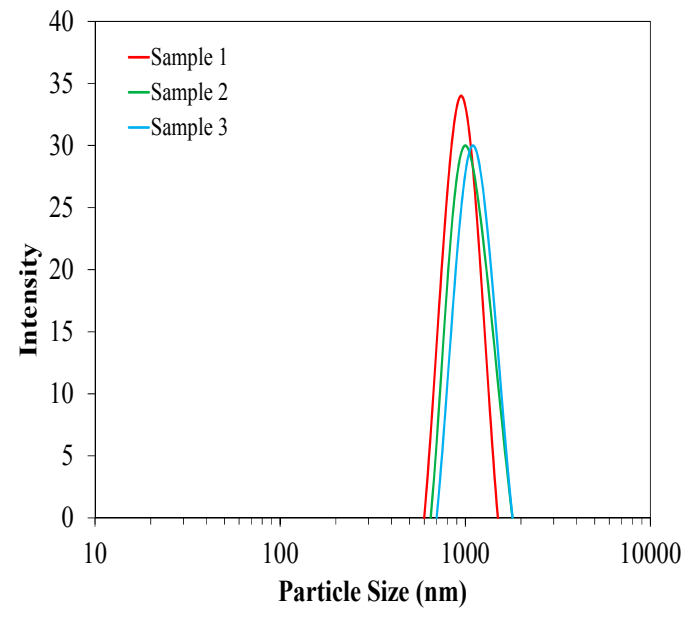

(a)

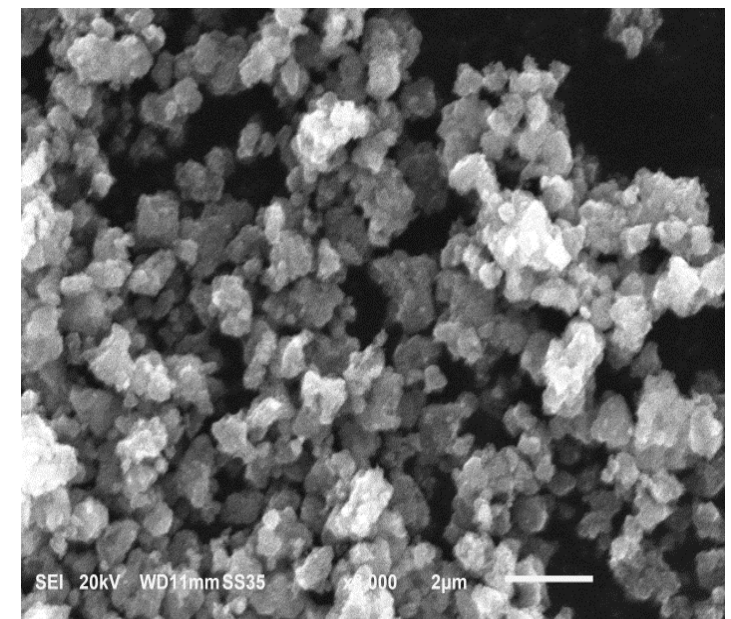

(b)

Figure 1. (a) Particle size distribution of $\mathrm{TiO}_{2}$ nanoparticles; (b) Scanning electron microscopy (SEM) image of $\mathrm{TiO}_{2}$ nanoparticles used in the experiment.

For cement mixture preparation, the nanoparticles were dispersed in water using ultrasonication for $30 \mathrm{~min}$, and then mixed for another two minutes with a mixer before adding to the cement mixture. Cement paste cubes with $25 \mathrm{~mm}$ dimensions at a 0.5 water-to-cement ratio were prepared in molds of steel and glass. Neat cement pastes and the cement pastes with $0.8 \%, 2.5 \%$, and $5 \%$, per cement mass, additions of $\mathrm{TiO}_{2}$ nanoparticles are denoted $\mathrm{CP}, 0.8 \% \mathrm{TiO}_{2}, 2.5 \% \mathrm{TiO}_{2}$, and $5 \% \mathrm{TiO}_{2}$, respectively. The cubes were cast in two layers, with each layer tamped 32 times by a $13 \mathrm{~mm}$ by $25 \mathrm{~mm}$ tamper. After casting, the cubes were cured in a room with more than $95 \%$ relative humidity and at a temperature of $23 \pm 2{ }^{\circ} \mathrm{C}$ for $24 \mathrm{~h}$. The cubes were then demolded and stored in a saturated lime solution until testing.

\subsection{Degree of Hydration}

The non-evaporable water content of the cement pastes was measured at 3 days, 14 days, and 28 days of curing. This non-evaporable water content corresponds to the amount of water bound in the chemical composition of the hydration product and allows for determining the degree of hydration of cementitious materials [17,44-48]. About $6 \mathrm{~g}$ of cement paste powder was prepared by grinding and passing through the sieve \#60. The powder was dried at $105^{\circ} \mathrm{C}$ for $24 \mathrm{~h}$ and then ignited for three hours at $1050{ }^{\circ} \mathrm{C}$. The non-evaporable water content $W_{\mathrm{n}}(\%)$ was computed from the following equation:

$$
W_{\mathrm{n}}=100 \times\left(\frac{m_{105}-m_{1050}}{m_{1050}}-L O I_{\mathrm{c}}\right)
$$


where $m_{105}$ is the mass of cement paste powder after drying at $105{ }^{\circ} \mathrm{C}(\mathrm{g}), m_{1050}$ is the mass of powder after ignition at $1050{ }^{\circ} \mathrm{C}(\mathrm{g})$, and $L O I_{\mathrm{C}}$ is the loss on ignition of the cement estimated to be $2.03 \%$ according to the manufacturer's specifications.

\subsection{Compressive Strength Test}

The compressive strength of the cement paste cubes was determined at 3 days, 14 days, and 28 days of curing. The compressive strength test was performed on a SATEC compression machine and the maximum compressive load sustained by each specimen was measured. The tests were conducted in stress-controlled conditions at a rate of $22 \mathrm{MPa} / \mathrm{min}$. The average of three identical specimens was calculated and reported.

\subsection{Electrical Resistivity Test}

The electrical resistivity of the neat cement paste and the cement pastes with $\mathrm{TiO}_{2}$ nanoparticles cured at varied temperatures, at 3 days, 14 days, and 28 days of curing, was measured using EIS. The EIS technique avoids some difficulty prevalent in electrical resistivity measurements using a direct current (DC) arising from charge transfer resistance at the electrodes [49,50]. In this method, the imaginary and real parts of the impedance response of the cement paste cubes are measured and used to determine electrical resistivity [51]. Cement pastes cubes were sandwiched between two metallic plate electrodes. A foam, pre-soaked in a $1 \mathrm{M}$ solution of $\mathrm{NaCl}$, was placed between each cube surface and the electrode, and compressed by a weight to ensure a good electrical contact between the electrodes and cube surfaces. EIS measurement was conducted using a Reference Gamry 600 potentiostat/galvanostat (Gamry Instruments, Warminster, PA, USA) at an AC voltage of $250 \mathrm{mV}$ and a frequency range of $10^{6}-10 \mathrm{~Hz}$. The electrical resistivity of the cement paste cubes was calculated as $\rho=R A / l$, where $A$ and $l$ are the cross sectional area and thickness of the cubes, respectively, and $R$ is the electrical resistance of the cube minus the electrical resistance of two wetted foams. The average electrical resistivity of three identical cubes was calculated and reported. Cement paste cubes, cured at elevated temperatures, were allowed to cool down to room temperature before their electrical resistivity was measured. This prevented the effect of temperature on the pore solution resistivity, thereby providing an accurate measurement of the electrical resistivity of the cement pastes.

\subsection{Porosity Measurement}

Porosity measurements were carried out using small samples with a thickness of 3-5 mm obtained from the center portion of the cement paste cubes at 3 days, 14 days, and 28 days of curing. The cement paste samples were submerged in acetone to stop hydration, dried in an oven at $60{ }^{\circ} \mathrm{C}$ for two days and their dry mass measured $\left(m_{d}\right)$. After samples were dried, they were saturated in methanol and their mass was measured until no change in mass was observed $\left(m_{s}\right)$. The volume $(V)$ of the samples was obtained using the Archimedes method in methanol. The porosity of the samples was measured as $\left(m_{s}-m_{d}\right) /\left(\rho_{\text {methanol }} V\right) \times 100$, where $\rho_{\text {methanol }}$ is methanol density. Porosity measurement was repeated for all samples and the average porosity was reported.

\subsection{X-ray Diffraction (XRD)}

The hydration product of the neat cement paste and cement paste modified with $0.8 \% \mathrm{TiO}_{2}$ nanoparticles cured at room temperature and $60^{\circ} \mathrm{C}$ was analyzed using XRD. The XRD analysis was performed on the cement pastes at 28 days of age. XRD is widely used in studying various phases in cementitious materials $[7,52,53]$. A small piece from the center of the cement paste cubes used in the compressive strength test was ground and passed through the sieve \#60. After drying for $24 \mathrm{~h}$ at $105^{\circ} \mathrm{C}$ in a vacuum oven, XRD was carried out using a Siemens 5000D X-ray diffractometer with the $\mathrm{Cu} \mathrm{K} \alpha$ radiation at a scan rate of 1.5 degree $/ \mathrm{min}$. 


\subsection{Microscopic Examination and Elemental Analysis}

Microscopic examination was conducted on the neat cement paste and the cement pastes with $0.8 \%$ $\mathrm{TiO}_{2}$ nanoparticles cured at room temperature and $60^{\circ} \mathrm{C}$, at 3 days and 28 days of curing. The sample preparation consisted of soaking small pieces of cement pastes in acetone to stop hydration, drying them at $60{ }^{\circ} \mathrm{C}$ for two days, and polishing them to achieve a very smooth surface finish. For polishing, samples were impregnated in a low viscosity epoxy and polished with SiC sand papers with 180, 300, 600, and 1200 grit sizes using ethanol as the lubricating medium. The samples were further polished using $1 \mu \mathrm{m}$ polycrystalline diamond paste abrasives and cleaned in an ultrasonicator for half an hour. Then, the samples were palladium coated and examined in SEM. The Energy dispersive X-ray spectroscopy (EDS) was used to obtain the elemental composition of the hydration product in the cement pastes.

\section{Results and Discussion}

\subsection{Degree of Hydration}

The non-evaporable water content $\left(W_{\mathrm{n}}\right)$ of the neat cement paste $(\mathrm{CP})$ and cement pastes modified with $0.8 \%, 2.5 \%$, and $5 \% \mathrm{TiO}_{2}$ nanoparticles cured at room temperature (RT), $40{ }^{\circ} \mathrm{C}$, and $60{ }^{\circ} \mathrm{C}$, at various ages, is shown in Figure 2. The results of curing at $40{ }^{\circ} \mathrm{C}$ corresponding to 3 days were not available due to equipment failure. It is observed that $W_{\mathrm{n}}$ increased with time in all cement pastes, as more hydration product was expected to form with time. The cement pastes cured at $60^{\circ} \mathrm{C}$ showed a slightly higher degree of hydration than the cement pastes cured at room temperature at all ages. This is due to the accelerating effect of temperature on the dissolution of cement clinkers resulting in enhanced hydration at this temperature [37]. It is seen that the cement pastes cured at $40^{\circ} \mathrm{C}$ experienced an increase in hydration compared to the cement paste cured at room temperature at early age, but the hydration increased at a slower rate after 14 days. The reduction in hydration rate in the cement pastes cured at $40^{\circ} \mathrm{C}$ after 14 days could be attributed to the microstructure evolution. It has been suggested that at elevated temperatures, hydration product forms a dense rim around cement particles $[34,41,42,54]$ decreasing the hydration rate of the remaining unhydrated cement particles after the initial increase in the hydration rate. It is expected that the above-mentioned microstructure evolution has also an effect on the hydration of the cement pastes cured at $60^{\circ} \mathrm{C}$; however, the increased diffusion rate through the dense rim at $60^{\circ} \mathrm{C}$ could explain the observed continued increase in the hydration of these cement pastes.

It can be seen that the addition of $\mathrm{TiO}_{2}$ nanoparticles increased the early hydration ( 3 days and 14 days) of the cement pastes cured at room temperature. This is attributed to the seeding effect of $\mathrm{TiO}_{2}$ nanoparticles providing heterogeneous nucleation sites for hydration products $[17,18]$. We noted that cement pastes modified with $\mathrm{TiO}_{2}$ nanoparticles generally showed a similar trend at early ages at curing temperatures corresponding to room temperature, $40^{\circ} \mathrm{C}$ and $60^{\circ} \mathrm{C}$. In other words, the influence of addition of $\mathrm{TiO}_{2}$ nanoparticles did not seem to show a distinct dependence on the temperatures used in this study. The hydration of cement is dominantly nucleation and growth controlled at the early ages and diffusion-controlled at later ages [15]. Since the effect of nanoparticles on hydration is primarily due to increased heterogeneous nucleation, it is expected that the enhancement in the hydration due to $\mathrm{TiO}_{2}$ nanoparticles does not depend on temperature after the first few days, where the hydration is primarily diffusion-controlled. 


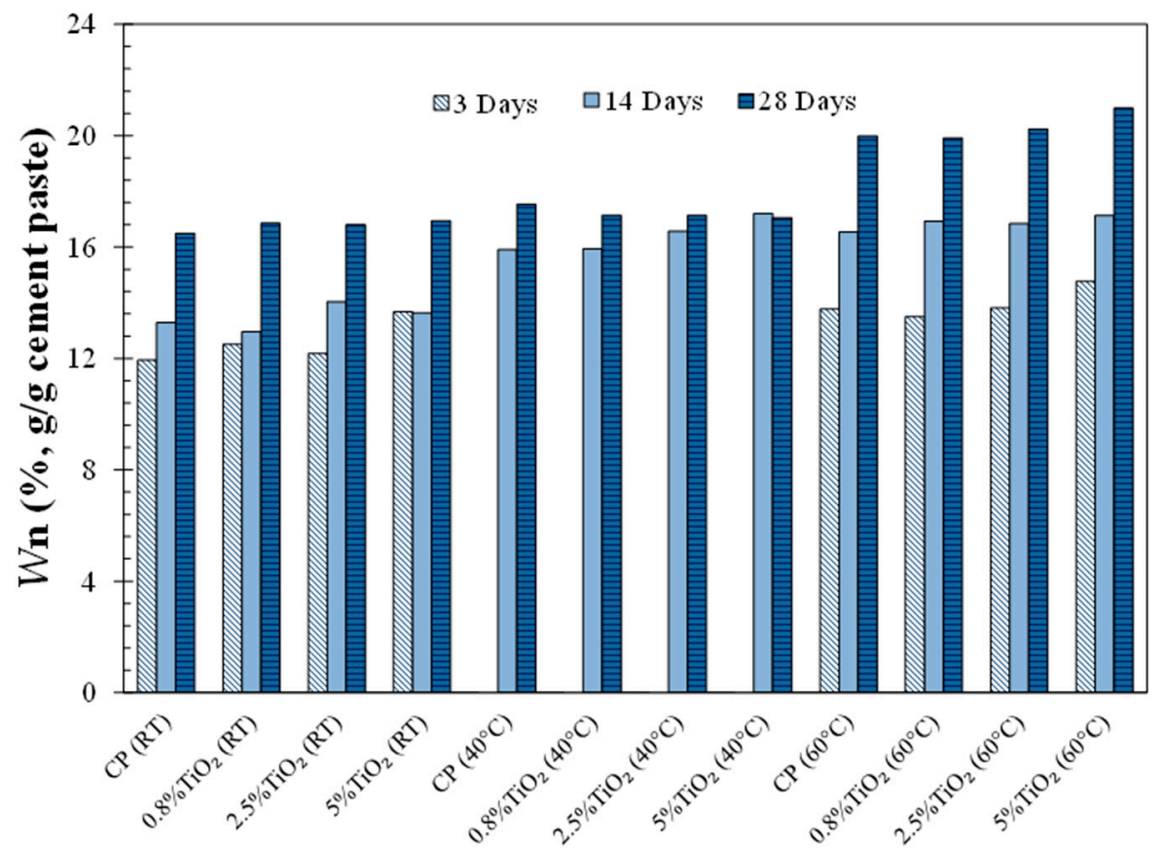

Figure 2. Non-evaporable water contents of the neat cement paste and the cement pastes modified with $0.8 \%, 2.5 \%$, and $5 \% \mathrm{TiO}_{2}$ nanoparticles, cured at varied temperatures (room temperature (RT), $40{ }^{\circ} \mathrm{C}$ and $\left.60^{\circ} \mathrm{C}\right)$, at different ages. CP: cement paste.

\subsection{Compressive Strength}

The compressive strength of the neat cement paste and the cement pastes modified with $\mathrm{TiO}_{2}$ nanoparticles is shown in Figure 3. It is noted that there is an increase in the compressive strength of the cement pastes cured at elevated temperatures at 3 days, and this increase was higher at $60^{\circ} \mathrm{C}$ than at $40{ }^{\circ} \mathrm{C}$. It is noted that the cement pastes cured at $40{ }^{\circ} \mathrm{C}$ exhibited a similar compressive strength to the cement paste cured at room temperature at 14 days and 28 days of curing indicating a reduction in the strength development of these cement pastes. The cement pastes cured at $60{ }^{\circ} \mathrm{C}$ showed a slower strength gain after the initial increase at 3 days and the compressive strength of these cement pastes was lower than the cement pastes cured at room temperature at 28 days.

The observed compressive strength behavior of the cement pastes cured at elevated temperatures is attributed to the microstructural changes resulting from the hydration process at elevated temperatures. Hydration at elevated temperatures promotes rapid formation of hydration product with a non-uniform distribution in the microstructure at the early age [34]. On the other hand, hydration at lower temperatures is expected to result in a more uniform distribution of hydration product in the microstructure since the hydration process takes place at a lower rate. The increase in the non-uniform distribution of phases in the microstructure tends to increase stress concentration in the microstructure due to mechanical property mismatch, thereby degrading the overall strength of the material [54]. This will be discussed later in the paper using the SEM microscopic examination. It is expected that the effect of high temperature hydration on compressive strength depends on temperature, and most likely, the mix design and chemical composition of cement.

It is noted that the cement pastes with $\mathrm{TiO}_{2}$ nanoparticles showed a slight improvement in compressive strength compared to the neat cement paste at early ages ( 3 days and 14 days). A similar improvement in compressive strength at early ages as a result of $\mathrm{TiO}_{2}$ nanoparticles addition was observed in the cement paste cured at $40^{\circ} \mathrm{C}$. However, it appears that the reduction in compressive strength at 28 days in high temperature cured cement pastes is more noticeable in the cement pastes with higher additions of $\mathrm{TiO}_{2}$ nanoparticles. This could be due to increased heterogeneity in the 
distribution of hydration products in these cement pastes amplifying stress concentrations in the microstructure, thereby reducing compressive strength.

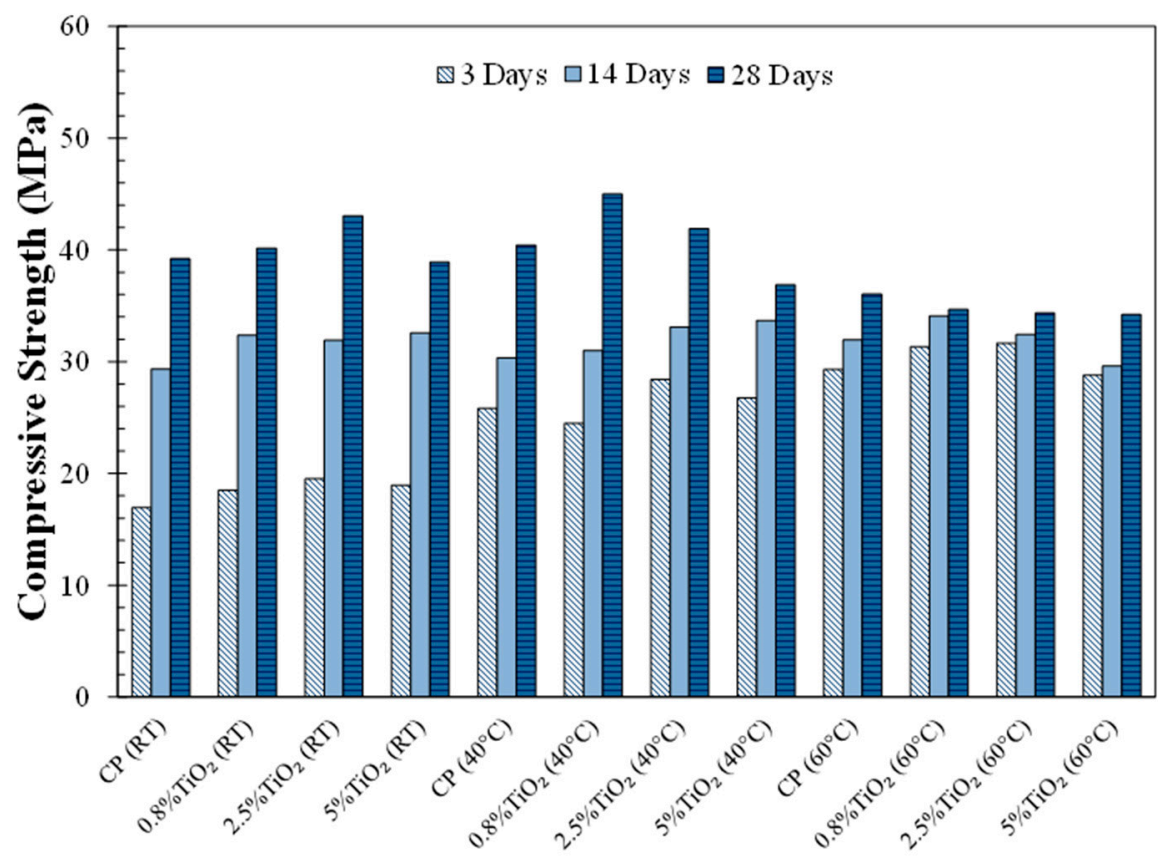

Figure 3. Compressive strengths of the cement pastes, cured at varied temperatures (room temperature (RT), $40^{\circ} \mathrm{C}$ and $60^{\circ} \mathrm{C}$ ), at 3 days, 14 days, and 28 days of age.

\subsection{Electrical Resistivity}

The electrical resistivities of the neat cement paste and the cement pastes with $\mathrm{TiO}_{2}$ nanoparticles are presented in Figure 4. It can be seen that the cement pastes cured at 40 and $60{ }^{\circ} \mathrm{C}$ experienced very little change in electrical resistivity between 14 days and 28 days, compared to the cement paste cured at room temperature where a gradual increase in the electrical resistivity was observed. There is a reduction in the electrical resistivity of the cement pastes cured at $40{ }^{\circ} \mathrm{C}$ compared to the room-temperature-cured cement pastes at all ages and this reduction is more pronounced at later ages. The cement pastes cured at $60{ }^{\circ} \mathrm{C}$ showed a similar electrical resistivity to the cement pastes cured at room temperature at early age, but the electrical resistivity decreased at later ages. The observed electrical resistivity results can be interpreted in view of the effect of high temperature curing on microstructure. In the cement pastes cured at $40{ }^{\circ} \mathrm{C}$, increased hydration rate could result in a loosely packed microstructure with less dense pore structure, leading to a decrease in the electrical resistivity at all ages as seen from the figure. In the cement paste cured at $60^{\circ} \mathrm{C}$, increased hydration rate at early age was higher than in the cement pastes cured at $40{ }^{\circ} \mathrm{C}$ resulting in the production of more hydration product and offsetting the effect of heterogeneity of the microstructure, leading to a similar electrical resistivity compared to the cement paste cured at room temperature at early age. However, as seen from the figure, at 28 days, the electrical resistivity of the cement pastes cured at $60{ }^{\circ} \mathrm{C}$ was lower than that of the room temperature cured cement paste indicating the dominant effect of the loosely packed microstructure of these cement pastes on the electrical resistivity at later ages.

It is noted that the addition of $\mathrm{TiO}_{2}$ nanoparticles is seen to generally lower the electrical resistivity of the cement pastes and this effect is more pronounced for the $60^{\circ} \mathrm{C}$ hydration. It appears that the addition of $\mathrm{TiO}_{2}$ nanoparticles increased the connectivity of the pore structure of the cement pastes. This is in agreement with the results of [21] but in contrast with other studies [20,32,33] where improved microstructure densification in the cement pastes modified with $\mathrm{TiO}_{2}$ nanoparticles was observed. The reduction in the electrical resistivity of the cement pastes with high additions of $\mathrm{TiO}_{2}$ nanoparticles 
cured at high temperatures at late ages is in agreement with the compressive strength results as shown in Figure 3, indicating a more loosely packed microstructure in these cement pastes.

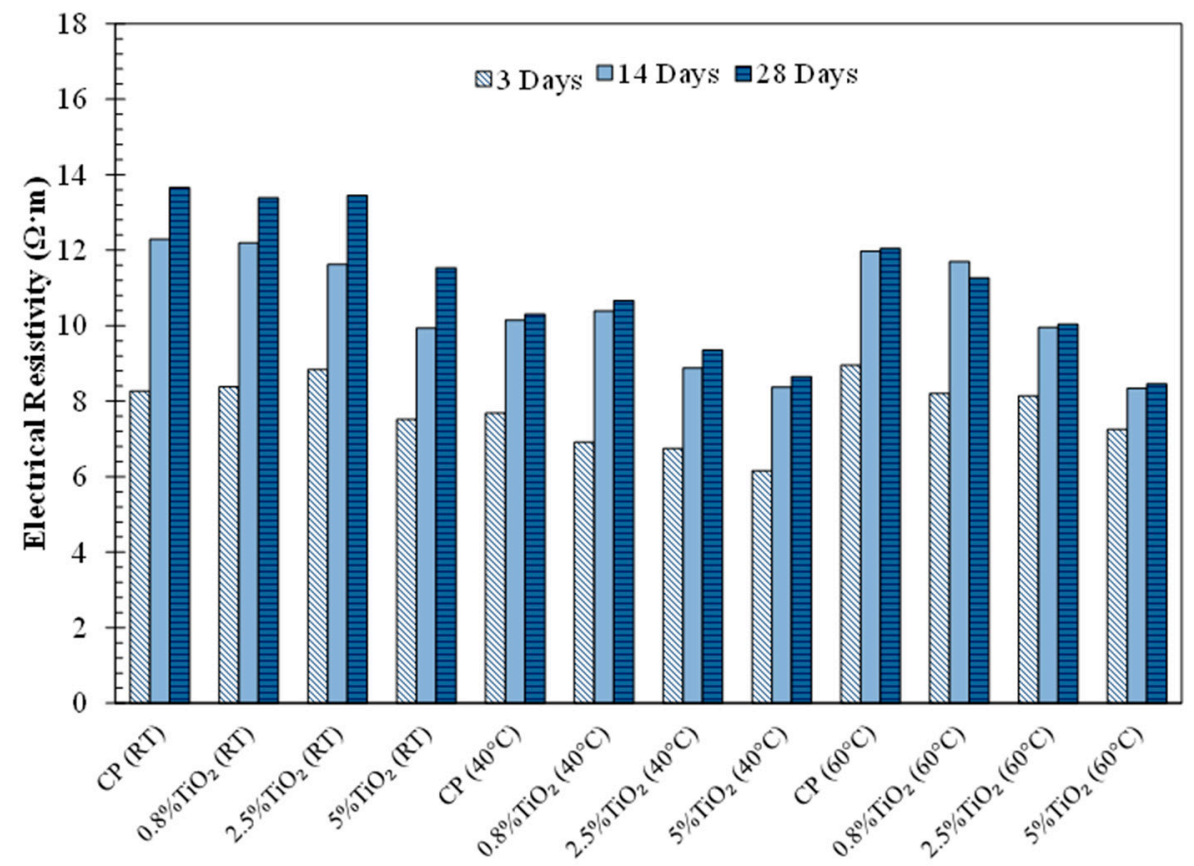

Figure 4. Electrical resistivity of the cement pastes, cured at varied temperatures (room temperature (RT), $40^{\circ} \mathrm{C}$ and $60^{\circ} \mathrm{C}$ ), at 3 days, 14 days, and 28 days of age.

\subsection{Porosity Measurement}

The porosity results of the neat cement paste and the cement pastes modified with $\mathrm{TiO}_{2}$ nanoparticles cured at room temperature, $40{ }^{\circ} \mathrm{C}$, and $60^{\circ} \mathrm{C}$ are presented in Figure 5. It is notable that there is a general reduction in porosity in the cement pastes cured at 40 and $60^{\circ} \mathrm{C}$ compared to the cement paste cured at room temperature. The decrease in porosity in the cement pastes cured at elevated temperatures could be attributed to an improved hydration rate at high temperatures producing more solid hydration product in the microstructure. It should be noted that the transport of cementitious material depends on the pore structure and pore solution chemistry, with the pore structure having a more pronounced role on transport behavior. In light of this, a comparison of the porosity and electrical resistivity results can be made. Porosity is a bulk material property indicating the total ratio of solid phase in the microstructure of the material. On the other hand, the electrical resistivity is highly dependent on the pore structure characteristics, such as pore size and connectivity. Thus, even though there is a reduction in porosity in the cement pastes cured at high temperatures, the electrical resistivity seemed to decrease as a result of the loosely packed microstructure of the cement pastes cured at high temperatures.

It can be seen that the addition of $\mathrm{TiO}_{2}$ nanoparticles was shown to generally decrease porosity at early age in most of the cement pastes, indicating improved hydration, as seen in Figure 2. However, this trend was reversed with an increase in curing time. 


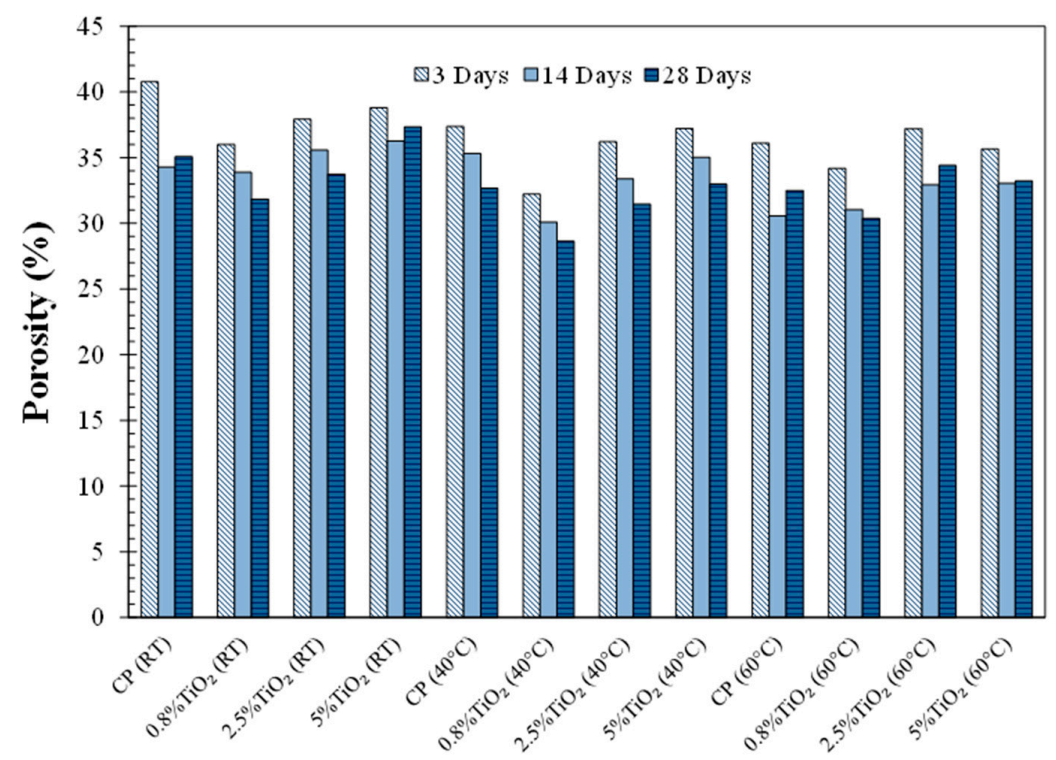

Figure 5. Porosity of the cement pastes, cured at varied temperatures (room temperature (RT), $40{ }^{\circ} \mathrm{C}$, and $60^{\circ} \mathrm{C}$ ), at 3 days, 14 days, and 28 days of age.

\subsection{XRD Analysis}

The XRD spectra of the neat cement paste and cement paste with $0.8 \% \mathrm{TiO}_{2}$ nanoparticles cured at room temperature and $60^{\circ} \mathrm{C}$ at 28 days of age are shown in Figure $6 \mathrm{a}, \mathrm{b}$, respectively. The peaks at $2 \theta$ of $18.00^{\circ}, 34.10^{\circ}, 47.12^{\circ}$, and $50.81^{\circ}$ correspond to calcium hydroxide [55]. It can be seen that the calcium hydroxide peaks are present in all cement pastes and exhibit a similar intensity to each other. Tricalcium silicate $\left(C_{3} S\right)$ and dicalcium silicate $\left(C_{2} S\right)$ have peaks in the $2 \theta$ range of $29^{\circ}-35^{\circ}$ [55]. $C_{3} S$ and $\mathrm{C}_{2} \mathrm{~S}$ constitute the primary components of cement clinkers and the weak peaks corresponding to these phases in the cement pastes indicate consumption of these phases during the hydration process. There is a weak peak at $2 \theta$ of $28.68^{\circ}$, which can be contributed to the presence of calcium-silicate-hydrate (C-S-H) in the microstructure of the cement pastes [4]. However, it should be noted that calcium hydroxide has a peak at $2 \theta$ of $28.75^{\circ}$ making difficult a certain identification of C-S-H at this peak. Comparing the XRD spectra of the cement pastes indicates no noticeable variation in the phases present in the microstructure of the cement pastes with and without $\mathrm{TiO}_{2}$ nanoparticles cured at different temperatures at 28 days of age. This indicates that high temperature curing of cement paste with $\mathrm{TiO}_{2}$ nanoparticles does not result in new phases in the hydration product or distinctly affect the phase composition of the hydration product.
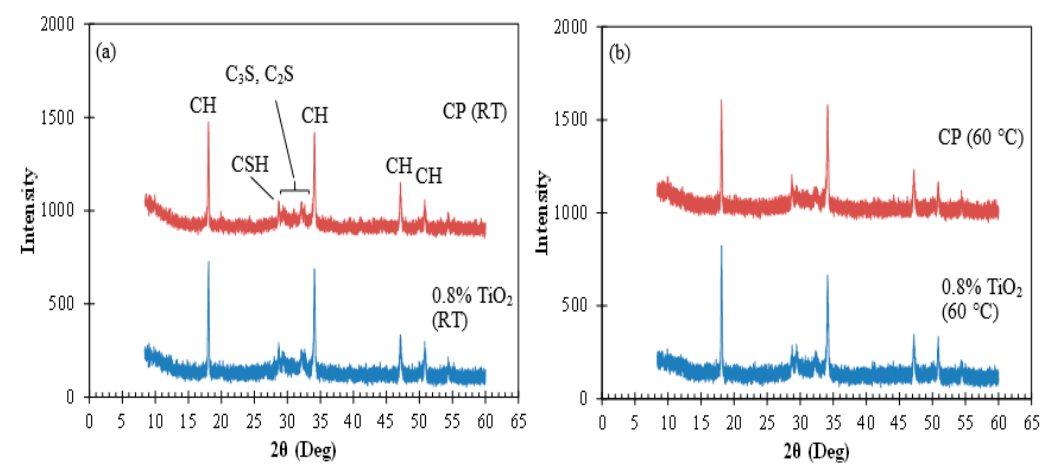

Figure 6. X-ray Diffraction (XRD) spectra of the neat cement paste and cement pastes with $0.8 \% \mathrm{TiO}_{2}$ nanoparticles cured at (a) room temperature and $(\mathbf{b})$ at $60^{\circ} \mathrm{C} . \mathrm{CH}$ : calcium hydroxide; $\mathrm{CSH}$ : calcium silicate hydrate; $\mathrm{C}_{3} \mathrm{~S}$ : tricalcium silicate; $\mathrm{C}_{2} \mathrm{~S}$ : dicalcium silicate. 


\subsection{Microscopic Examination}

The SEM micrographs of the neat cement paste and cement paste with $0.8 \% \mathrm{TiO}_{2}$ nanoparticles cured at room temperature (RT) and $60^{\circ} \mathrm{C}$, at 3 days and 28 days of curing, are shown in Figures 7 and 8 , respectively. An example of an unhydrated cement particle, hydration product and capillary pores is shown in Figure 7a. A general improvement in the densification of the microstructure from 3 days to 28 days can be seen in these micrographs. A dense rim of hydration product, mostly composed of calcium-silicate-hydrate (C-S-H), is seen to have formed around cement particles in the microstructure of the cement pastes cured at $60^{\circ} \mathrm{C}$, as marked in Figures $7 \mathrm{c}$ and $8 \mathrm{c}$. The microstructure of the cement pastes cured at $60^{\circ} \mathrm{C}$ consisted of dense regions and macropores dispersed in the microstructure. On the other hand, the cement paste cured at room temperature appeared to have a porous microstructure with more uniformly distributed capillary pores. The initial microstructure densification, as a result of curing at high temperature, can explain the initial increase in the compressive strength of the cement pastes, as shown in Figure 3. The increase in the heterogeneity of the phases in the microstructure of hydration product in the cement pastes cured at $60{ }^{\circ} \mathrm{C}$ increases the mismatch in mechanical properties and stress concentration at the microscale. This could explain the relatively small increase in the compressive strength of the cement pastes cured at $60{ }^{\circ} \mathrm{C}$ after 3 days, as seen in Figure 3. No significant variation in the morphological features of the cement pastes with and without $\mathrm{TiO}_{2}$ nanoparticles can be inferred from these micrographs cured at room temperature or $60{ }^{\circ} \mathrm{C}$.
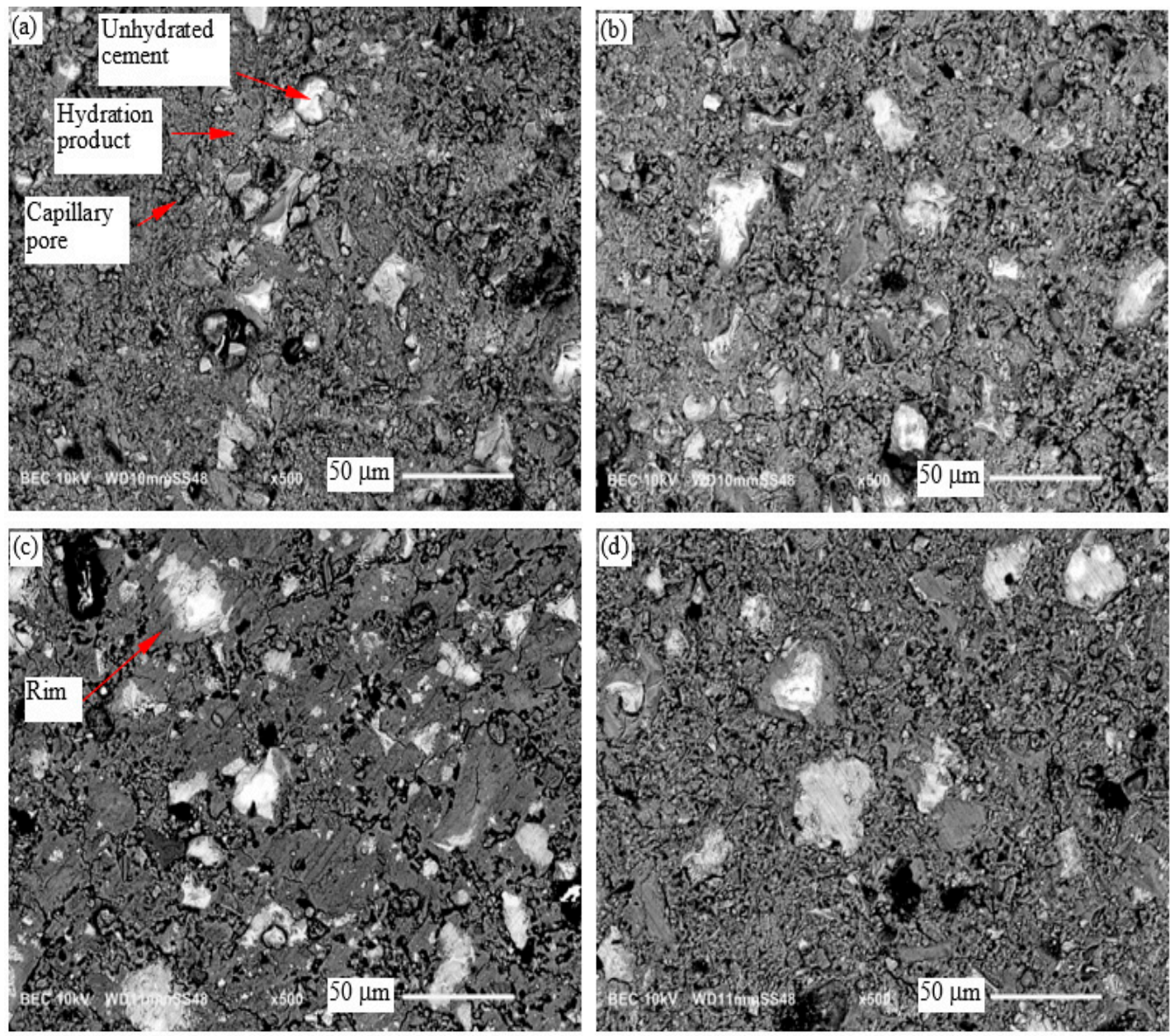

Figure 7. SEM micrographs showing the microstructure at 3 days of (a) the neat cement paste; (b) cement paste with $0.8 \% \mathrm{TiO}_{2}$ nanoparticles, respectively, cured at room temperature; (c) the neat cement paste; and (d) cement paste with $0.8 \% \mathrm{TiO}_{2}$ nanoparticles, cured at $60{ }^{\circ} \mathrm{C}$. 

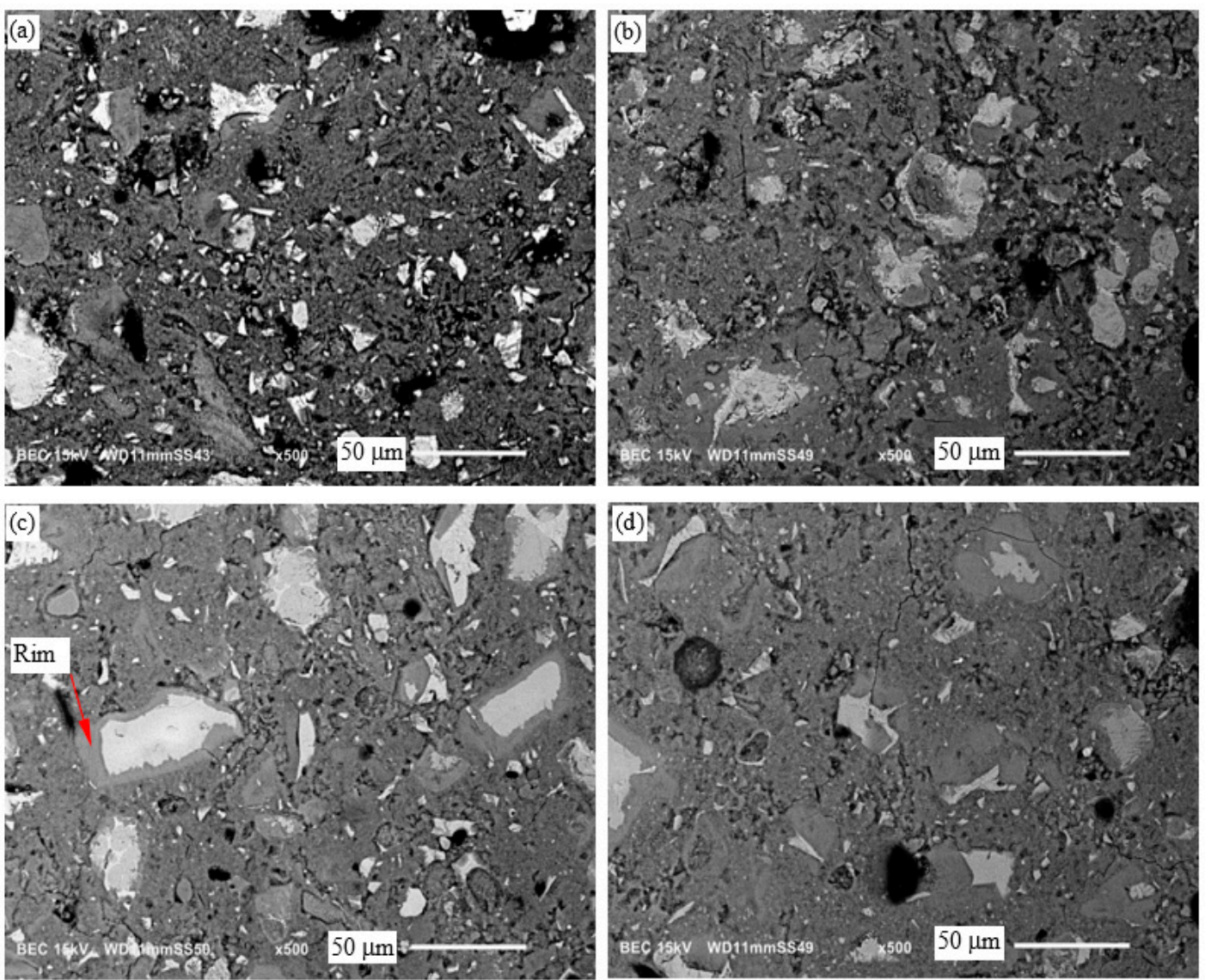

Figure 8. SEM micrographs showing the microstructure at 28 days of (a) the neat cement paste; (b) cement paste with $0.8 \% \mathrm{TiO}_{2}$ nanoparticles, respectively, cured at room temperature; (c) the neat cement paste; and (d) cement paste with $0.8 \% \mathrm{TiO}_{2}$ nanoparticles, cured at $60{ }^{\circ} \mathrm{C}$.

The results of the EDS elemental analysis of the hydration product are shown in Table 2. There appears to be a slight increase in the atomic ratio $\mathrm{Ca} / \mathrm{Si}$ of hydration product cured at $60{ }^{\circ} \mathrm{C}$ compared to room temperature. On the other hand, atomic ratio $\mathrm{Al} / \mathrm{Ca}$ seems to be lower at $60{ }^{\circ} \mathrm{C}$ curing than at room temperature curing. An increase in $\mathrm{Ca} / \mathrm{Si}$ ratio and a decrease in $\mathrm{Al} / \mathrm{Ca}$ ratio at high temperature curing has been noted in prior investigations [34,40,56,57]. A possible explanation for this observation has been suggested to be more interspersed mixing of C-S-H gels and $\mathrm{Ca}(\mathrm{OH})_{2}$ in the cement pastes cured at high temperatures [40,56]. It is noted from Table 2 that the difference in the atomic ratios $\mathrm{Ca} / \mathrm{Si}$ and $\mathrm{Al} / \mathrm{Ca}$ between the hydration product in the rim around cement particles and away from cement particles is insignificant, and this is in agreement with the prior studies [56]. The observed difference in the color of the hydration product in the rim and away from cement particles in the backscatter SEM images has been attributed to the difference in porosity and water content and not the chemical composition of the hydration product [56].

Table 2. Energy dispersive X-ray spectroscopy (EDS) elemental analysis of the hydration product. $\mathrm{CP}$ : cement paste. RT: room temperature.

\begin{tabular}{ccccc}
\hline \multirow{2}{*}{ Sample } & \multicolumn{4}{c}{ Rim } \\
\cline { 2 - 5 } & $\mathrm{Ca} / \mathrm{Si}$ & $\mathbf{A l} / \mathbf{C a}$ & $\mathbf{C a} / \mathbf{S i}$ & $\mathbf{A l} / \mathbf{C a}$ \\
\hline $\mathrm{CP}(\mathrm{RT})$ & 1.90 & 0.06 & - & - \\
$0.8 \% \mathrm{TiO}_{2}(\mathrm{RT})$ & 1.81 & 0.08 & - & - \\
$\mathrm{CP}\left(60^{\circ} \mathrm{C}\right)$ & 1.99 & 0.04 & 1.95 & 0.04 \\
$0.8 \% \mathrm{TiO}_{2}\left(60^{\circ} \mathrm{C}\right)$ & 1.97 & 0.05 & 1.89 & 0.04 \\
\hline
\end{tabular}




\section{Conclusions}

In this study, the effect of curing at elevated temperatures on the hydration, microstructure, compressive strength, and transport of cement paste modified with $\mathrm{TiO}_{2}$ nanoparticles was investigated. Based on the results obtained from this study, the following conclusions can be drawn:

- Temperature generally tends to increase the early hydration of the cement paste and cement pastes with $\mathrm{TiO}_{2}$ nanoparticles.

- It was observed that the cement pastes cured at elevated temperatures exhibited a rise in compressive strength at early age, but the rate of strength gain decreased at later ages more noticeably at a curing temperature of $60^{\circ} \mathrm{C}$ than at $40^{\circ} \mathrm{C}$.

- The electrical resistivity of the cement pastes cured at elevated temperatures was shown to exhibit insignificant change after 14 days of curing. At 28 days, the electrical resistivity of these cement pastes was decreased compared to that of the cement paste cured at room temperature. It was suggested that a competition between improved hydration and non-uniform distribution of the hydration product in the microstructure appeared to determine the electrical resistivity of the cement pastes cured at elevated temperatures.

- The porosity of the cement pastes cured at elevated temperatures was shown to be generally lower than that of the cement paste cured at room temperature. The contrast between the porosity and electrical resistivity results is explained due to the dominant effect of pore structure and non-uniform distribution of hydration product on the transport behavior of cement pastes cured at elevated temperatures.

- Microstructural examination indicated a more uniformly distributed hydration product in the cement pastes cured at room temperature than in the cement pastes cured at $60^{\circ} \mathrm{C}$.

- It was observed that the effect of high temperature curing on reducing the compressive strength and electrical resistivity of the cement pastes at late ages was more pronounced with higher levels of added $\mathrm{TiO}_{2}$ nanoparticles.

Acknowledgments: Some of the experiments in this study were performed in the Structures and Materials Laboratory at the University of Miami and this is hereby acknowledged. Mahsa Kamali is thanked for assistance with SEM microscopy. Yara Wehbe is thanked for helping with some of sample preparations.

Author Contributions: Ali Ghahremaninezhad conceived and designed the experiments; Karine Pimenta Teixeira, Isadora Perdigão Rocha, Leticia De Sá Carneiro and Jessica Flores performed the experiments; Ali Ghahremaninezhad and Jessica Flores analyzed the data; Edward Dauer contributed analysis tools; Ali Ghahremaninezhad wrote the paper.

Conflicts of Interest: The authors declare no conflict of interest.

\section{References}

1. Sanchez, F.; Sobolev, K. Nanotechnology in concrete-A review. Constr. Build. Mater. 2010, 24, $2060-2071$. [CrossRef]

2. Chen, J.; Poon, C.S. Photocatalytic activity of titanium dioxide modified concrete materials-Influence of utilizing recycled glass cullets as aggregates. J. Environ. Manag. 2009, 90, 3436-3442. [CrossRef] [PubMed]

3. Chen, J.; Kou, S.; Poon, C. Photocatalytic cement-based materials: Comparison of nitrogen oxides and toluene removal potentials and evaluation of self-cleaning performance. Build. Environ. 2011, 46, 1827-1833. [CrossRef]

4. Aly, M.; Hashmi, M.S.J.; Olabi, A.G.; Messeiry, M.; Hussain, A.I. Effect of nano clay particles on mechanical, thermal and physical behaviours of waste-glass cement mortars. Mater. Sci. Eng. A 2011, 528, 7991-7998. [CrossRef]

5. Senff, L.; Labrincha, J.A.; Ferreira, V.M.; Hotza, D.; Repette, W.L. Effect of nano-silica on rheology and fresh properties of cement pastes and mortars. Constr. Build. Mater. 2009, 23, 2487-2491. [CrossRef] 
6. Gao, K.; Lin, K.L.; Wang, D.; Hwang, C.L.; Tuan, B.L.; Shiu, H.S.; Cheng, T.W. Effect of nano-SiO 2 on the alkali-activated characteristics of metakaolin-based geopolymers. Constr. Build. Mater. 2013, 48, 441-447. [CrossRef]

7. Hou, P.K.; Kawashima, S.; Wang, K.J.; Corr, D.J.; Qian, J.S.; Shah, S.P. Effects of colloidal nanosilica on rheological and mechanical properties of fly ash-cement mortar. Cem. Concr. Compos. 2013, 35, 12-22. [CrossRef]

8. Singh, L.P.; Goel, A.; Bhattacharyya, S.K.; Sharma, U.; Mishra, G.; Singh, L.P.; Goel, A.; Bhattacharyya, S.K.; Sharma, U.; Mishra, G. Hydration studies of cementitious material using silica nanoparticles. J. Adv. Concr. Technol. 2015, 13, 345-354. [CrossRef]

9. Singh, L.P.; Goel, A.; Bhattachharyya, S.K.; Ahalawat, S. Effect of morphology and dispersibility of silica nanoparticles on the mechanical behaviour of cement mortar. Int. J. Concr. Struct. Mater. 2015, 9, 207-217. [CrossRef]

10. Kawashima, S.; Hou, P.; Corr, D.J.; Shah, S.P. Modification of cement-based materials with nanoparticles. Cem. Concr. Compos. 2013, 36, 8-15. [CrossRef]

11. Li, G.Y.; Wang, P.M.; Zhao, X. Mechanical behavior and microstructure of cement composites incorporating surface-treated multi-walled carbon nanotubes. Carbon 2005, 43, 1239-1245. [CrossRef]

12. Konsta-Gdoutos, M.S.; Metaxa, Z.S.; Shah, S.P. Multi-scale mechanical and fracture characteristics and early-age strain capacity of high performance carbon nanotube/cement nanocomposites. Cem. Concr. Compos. 2010, 32, 110-115. [CrossRef]

13. De Ibarra, Y.S.; Gaitero, J.J.; Erkizia, E.; Campillo, I. Atomic force microscopy and nanoindentation of cement pastes with nanotube dispersions. Phys. Status Solidi 2006, 203, 1076-1081. [CrossRef]

14. Lackhoff, M.; Prieto, X.; Nestle, N.; Dehn, F.; Niessner, R. Photocatalytic activity of semiconductor-modified cement-Influence of semiconductor type and cement ageing. Appl. Catal. B Environ. 2003, 43, 205-216. [CrossRef]

15. Jayapalan, A.R.; Lee, B.Y.; Fredrich, S.M.; Kurtis, K.E. Influence of Additions of Anatase $\mathrm{TiO}_{2}$ Nanoparticles on Early-Age Properties of Cement-Based Materials. Transp. Res. Rec. J. Transp. Res. Board. 2010, 2141, 41-46. [CrossRef]

16. Lee, B.Y.; Kurtis, K.E. Influence of $\mathrm{TiO}_{2}$ nanoparticles on early $\mathrm{C}_{3}$ S hydration. J. Am. Ceram. Soc. 2010, 93, 3399-3405. [CrossRef]

17. Chen, J.; Kou, S.C.; Poon, C.S. Hydration and properties of nano- $\mathrm{TiO}_{2}$ blended cement composites. Cem. Concr. Compos. 2012, 34, 642-649. [CrossRef]

18. Lee, B.Y.; Jayapalan, A.R.; Kurtis, K.E. Effects of nano- $\mathrm{TiO}_{2}$ on properties of cement-based materials. Mag. Concr. Res. 2013, 65, 1293-1302. [CrossRef]

19. Zhang, R.; Cheng, X.; Hou, P.; Ye, Z. Influences of nano- $\mathrm{TiO}_{2}$ on the properties of cement-based materials: Hydration and drying shrinkage. Constr. Build. Mater. 2015, 81, 35-41. [CrossRef]

20. Ma, B.; Li, H.; Mei, J.; Li, X.; Chen, F. Effects of nano-TiO ${ }_{2}$ on the toughness and durability of cement-based material. Adv. Mater. Sci. Eng. 2015, 2015, 583106. [CrossRef]

21. Martins, T.; Torgal, F.P.; Miraldo, S.; Aguiar, J.B.; Carlos, J. An experimental investigation on nano-TiO 2 and fly ash based high performance concrete. Indian Concr. J. 2016, 90, 1-9.

22. Bost, P.; Regnier, M.; Horgnies, M. Comparison of the accelerating effect of various additions on the early hydration of Portland cement. Constr. Build. Mater. 2016, 113, 290-296. [CrossRef]

23. Nazari, A. The effects of curing medium on flexural strength and water permeability of concrete incorporating $\mathrm{TiO}_{2}$ nanoparticles. Mater. Struct. 2011, 44, 773-786. [CrossRef]

24. Liu, J.; Li, Q.; Xu, S. Influence of nanoparticles on fluidity and mechanical properties of cement mortar. Constr. Build. Mater. 2015, 101, 892-901. [CrossRef]

25. Feng, D.; Xie, N.; Gong, C.; Leng, Z.; Xiao, H.; Li, H. Portland cement paste modified by $\mathrm{TiO}_{2}$ nanoparticles: A microstructure perspective. Ind. Eng. Chem. Res. 2013, 52, 11575-11582. [CrossRef]

26. Strawhecker, K.E.; Manias, E. Structure and properties of poly (vinyl alcohol )/ $\mathrm{Na}^{+}$montmorillonite nanocomposites. Chem. Mater. 2000, 12, 2943-2949. [CrossRef]

27. Podsiadlo, P.; Kaushik, A.K.; Arruda, E.M.; Waas, A.M.; Shim, B.S.; Xu, J.; Nandivada, H.; Pumplin, B.G.; Lahann, J.; Ramamoorthy, A.; et al. Ultrastrong and stiff layered polymer nanocomposites. Science 2007, 318, 80-83. [CrossRef] [PubMed] 
28. Prasanth, R.; Shubha, N.; Hng, H.H.; Srinivasan, M. Effect of nano-clay on ionic conductivity and electrochemical properties of poly(vinylidene fluoride) based nanocomposite porous polymer membranes and their application as polymer electrolyte in lithium ion batteries. Eur. Polym. J. 2013, 49, 307-318. [CrossRef]

29. Hakamy, A.; Shaikh, F.U.A.; Low, I.M. Effect of calcined nanoclay on microstructural and mechanical properties of chemically treated hemp fabric-reinforced cement nanocomposites. Constr. Build. Mater. 2015, 95, 882-891. [CrossRef]

30. Chen, J.; Poon, C. Photocatalytic construction and building materials: From fundamentals to applications. Build. Environ. 2009, 44, 1899-1906. [CrossRef]

31. Hüsken, G.; Hunger, M.; Brouwers, H.J.H. Experimental study of photocatalytic concrete products for air purification. Build. Environ. 2009, 44, 2463-2474. [CrossRef]

32. Yang, L.Y.; Jia, Z.J.; Zhang, Y.M.; Dai, J.G. Effects of nano- $\mathrm{TiO}_{2}$ on strength, shrinkage and microstructure of alkali activated slag pastes. Cem. Concr. Compos. 2015, 57, 1-7. [CrossRef]

33. Mohseni, E.; Naseri, F.; Amjadi, R.; Khotbehsara, M.M.; Ranjbar, M.M. Microstructure and durability properties of cement mortars containing. Constr. Build. Mater. 2016, 114, 656-664. [CrossRef]

34. Elkhadiri, I.; Palacios, M.; Puertas, F. Effect of curing temperature on cement hydration. Ceram. Silik. 2009, 53, 65-75.

35. Price, W. Factors influencing concrete strength. ACI J. 1951, 47, 417-432.

36. Escalante-García, J.I.; Sharp, J.H. The microstructure and mechanical properties of blended cements hydrated at various temperatures. Cem. Concr. Res. 2001, 31, 695-702. [CrossRef]

37. Lothenbach, B.; Winnefeld, F.; Alder, C.; Wieland, E.; Lunk, P. Effect of temperature on the pore solution, microstructure and hydration products of Portland cement pastes. Cem. Concr. Res. 2007, 37, 483-491. [CrossRef]

38. De Weerdt, K.; Haha, M.B.; le Saout, G.; Kjellsen, K.O.; Justnes, H.; Lothenbach, B. Hydration mechanisms of ternary Portland cements containing limestone powder and fly ash. Cem. Concr. Res. 2011, 41, 279-291. [CrossRef]

39. Ballester, P.; Hidalgo, A.; Mármol, I.; Morales, J.; Sánchez, L. Effect of brief heat-curing on microstructure and mechanical properties in fresh cement based mortars. Cem. Concr. Res. 2009, 39, 573-579. [CrossRef]

40. Elkhadiri, I.; Puertas, F. The effect of curing temperature on sulphate-resistant cement hydration and strength. Constr. Build. Mater. 2008, 22, 1331-1341. [CrossRef]

41. Kjellsen, K.O.; Detwiler, R.J.; Gjørv, O.E. Development of microstructures in plain cement pastes hydrated at different temperatures. Cem. Concr. Res. 1991, 21, 179-189. [CrossRef]

42. Kjellsen, K.O.; Detwiler, R.J. Reaction kinetics of Portland cement mortars hydrated at different temperatures. Cem. Concr. Res. 1992, 22, 112-120. [CrossRef]

43. Jayapalan, A.R.; Jue, M.L.; Kurtis, K.E. Nanoparticles and apparent activation energy of Portland cement. J. Am. Ceram. Soc. 2014, 97, 1534-1542. [CrossRef]

44. Hou, P.; Kawashima, S.; Kong, D.; Corr, D.J.; Qian, J.; Shah, S.P. Modification effects of colloidal nanoSiO ${ }_{2}$ on cement hydration and its gel property. Compos. Part B Eng. 2013, 45, 440-448. [CrossRef]

45. Schwarz, N.; DuBois, M.; Neithalath, N. Electrical conductivity based characterization of plain and coarse glass powder modified cement pastes. Cem. Concr. Compos. 2007, 29, 656-666. [CrossRef]

46. Neithalath, N.; Persun, J.; Hossain, A. Hydration in high-performance cementitious systems containing vitreous calcium aluminosilicate or silica fume. Cem. Concr. Res. 2009, 39, 473-481. [CrossRef]

47. Bu, Y.; Weiss, J. The influence of alkali content on the electrical resistivity and transport properties of cementitious materials. Cem. Concr. Compos. 2014, 51, 49-58. [CrossRef]

48. Feng, X.; Garboczi, E.J.; Bentz, D.P.; Stutzman, P.E.; Mason, T.O. Estimation of the degree of hydration of blended cement pastes by a scanning electron microscope point-counting procedure. Cem. Concr. Res. 2004, 34, 1787-1793. [CrossRef]

49. Jain, J.A.; Neithalath, N. Chloride transport in fly ash and glass powder modified concretes-Influence of test methods on microstructure. Cem. Concr. Compos. 2010, 32, 148-156. [CrossRef]

50. Neithalath, N.; Weiss, J.; Olek, J. Characterizing Enhanced Porosity concrete using electrical impedance to predict acoustic and hydraulic performance. Cem. Concr. Res. 2006, 36, 2074-2085. [CrossRef] 
51. Snyder, K.A.; Ferraris, C.; Martys, N.S.; Garboczi, E.J. Using impedance spectroscopy to assess the viability of the rapid chloride test for determining concrete conductivity. J. Res. Natl. Inst. Stand. Technol. 2000, 105, 497. [CrossRef] [PubMed]

52. Chindaprasirt, P.; Jaturapitakkul, C.; Sinsiri, T. Effect of fly ash fineness on microstructure of blended cement paste. Constr. Build. Mater. 2007, 21, 1534-1541. [CrossRef]

53. Aly, M.; Hashmi, M.S.; Olabi, A.G.; Messeiry, M.; Abadir, E.F.; Hussain, A.I. Effect of colloidal nano-silica on the mechanical and physical behaviour of waste-glass cement mortar. Mater. Des. 2012, 33, 127-135. [CrossRef]

54. Patel, H.H.; Bland, C.H.; Poole, A.B. The microstructure of concrete cured at elevated temperatures. Cem. Concr. Res. 1995, 25, 485-490. [CrossRef]

55. Joint Committee on Powder Diffraction Standards; JCPDS-International Center for Diffraction Data: Newtown Square, PA, USA, 2000.

56. Famy, C.; Scrivener, K.L.; Crumbie, A.K. What causes differences of C-S-H gel grey levels in backscattered electron images? Cem. Concr. Res. 2002, 32, 1465-1471. [CrossRef]

57. Taylor, H.F.W. Nanostructure of C-S-H: Current status. Adv. Cem. Based Mater. 1993, 1, 38-46. [CrossRef]

(C) 2016 by the authors; licensee MDPI, Basel, Switzerland. This article is an open access article distributed under the terms and conditions of the Creative Commons Attribution (CC-BY) license (http://creativecommons.org/licenses/by/4.0/). 